\title{
Estimating Kinetic Parameters for Essential Amino Acid Production in Arabidopsis Thaliana by Using Particle Swarm Optimization
}

\author{
Siew Teng Nga, Chuii Khim Chonga, Yee Wen Choona, Lian En Chaia, Safaai Derisa, Rosli Md Illias ${ }^{b}$, Mohd Shahir Shamsirc, Mohd \\ Saberi Mohamada* \\ ${ }^{a}$ Artificial Intelligence and Bioinformatics Research Group, Faculty of Computing, UniversitiTeknologi Malaysia, 81310 UTM Johor Bahru, Johor, \\ Malaysia \\ ${ }^{b}$ Department of Bioprocess Engineering, Faculty of Chemical Engineering, UniversitiTeknologi Malaysia, UTM Johor Bahru, Johor, Malaysia \\ ¿Bioinformatics Research Group, Faculty of Biosciences and Medical Engineering, Universiti Teknologi Malaysia, UTM Johor Bahru, Johor, Malaysia \\ *Corresponding author: saberi@utm.my
}

\section{Article history}

Received :17 May 2013

Received in revised form :

21 July 2013

Accepted :15 August 2013

\section{Graphical abstract}

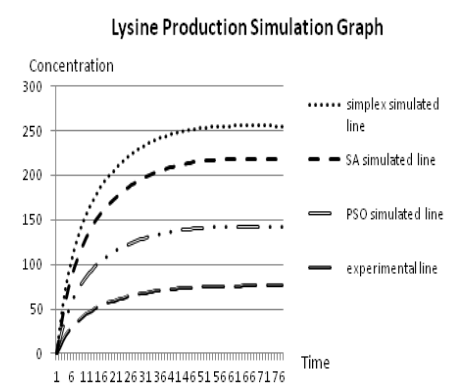

\begin{abstract}
Parameter estimation is one of nine phases in modelling, which is the most challenging task that is used to estimate the parameter values for biological system that is non-linear. There is no general solution for determining the nonlinearity of the dynamic model. Experimental measurement is expensive, hard and time consuming. Hence, the aim for this research is to implement Particle Swarm Optimization (PSO) intoSBToolbox to solve the mentioned problems. As a result, the optimum kinetic parameters for simulating essential amino acid metabolism in plant model Arabidopsis Thaliana are obtained. There are four performance measurements used, namely computational time, average of error rate, standard deviation and production of graph. As a finding of this research, PSO has the smallest standard deviation and average of error rate. The computational time in parameter estimation is smaller in comparison with others, indicating that PSO is a consistent method to estimate parameter values compared to the performance of Simulated Annealing (SA) and downhill simplex method after the implementation into SBToolbox.
\end{abstract}

Keywords: Parameter estimation; PSO; SBToolbox; Arabidopsis Thaliana

\begin{abstract}
Abstrak
Anggaran parameter adalah salah satu daripada sembilan fasa dalam model, yang merupakan tugas yang paling mencabar yang digunakan untuk menganggarkan nilai parameter bagi sistem biologi yang tidak linear. Tiada penyelesaian am bagi menentukan ketidaklurusan model yang dinamik. Eksperimen yang dijalankan dalam makmal adalah mahal, sukar dan menggunakan masa yang lama. Oleh itu, tujuan kajian ini adalah untuk melaksanakan Particle Swarm Optimization (PSO) ke SBToolbox bagi menyelesaikan masalah-masalah yang diyatakan. Terdapat empat ukuran prestasi yang digunakan, iaitu masa, pengiraan, purata kadar kesilapan, sisihan piawai dan pengeluaran graf. Sebagai keputusan penyelidikan, PSO mempunyai sisihan terkecil standard dan purata kadar kesilapan. Masa pengiraan dalam anggaran parameter adalah lebih kecil berbanding dengan algorithm lain, menunjukkan bahawa PSO adalah kaedah yang konsisten untuk menganggarkan nilai-nilai parameter berbanding prestasinya dengan Simulated Annealing (SA) dan 'downhill simplex method' dalam SBToolbox.
\end{abstract}

Kata kunci: Anggaran parameter; PSO; SBToolbox; Arabidopsis Thaliana

C 2013 Penerbit UTM Press. All rights reserved.

\subsection{INTRODUCTION}

It is complex to understand the regulation, structure and organization of the underlying biological system because it needs quantitative assessment and reliable understanding of the system functions [1].

Modelling is a process to transform the symbol model into a numerical model which enables us to understand the model deeply. It converts the biological system into a simple analogy that is easier to analyze, interrogate, predict, extrapolate, manipulate, and optimize than the biological system itself. There are 9 phases in mathematical modelling as shown in Figure 1 according to Chou and Voit [2].

At molecular level, the variables represent the concentration of chemical species such as protein, mRNA and so on. With the known pathway structure, we are able to write down the equation, which depends on several parameters. The parameters might be the reaction rate, production and decay coefficient, approximation or 
reduction that is satisfied by the structure of the system. Normally, the parameters are unknown. The measurement, if done experimentally, is expensive, hard and time consuming [3, 4].

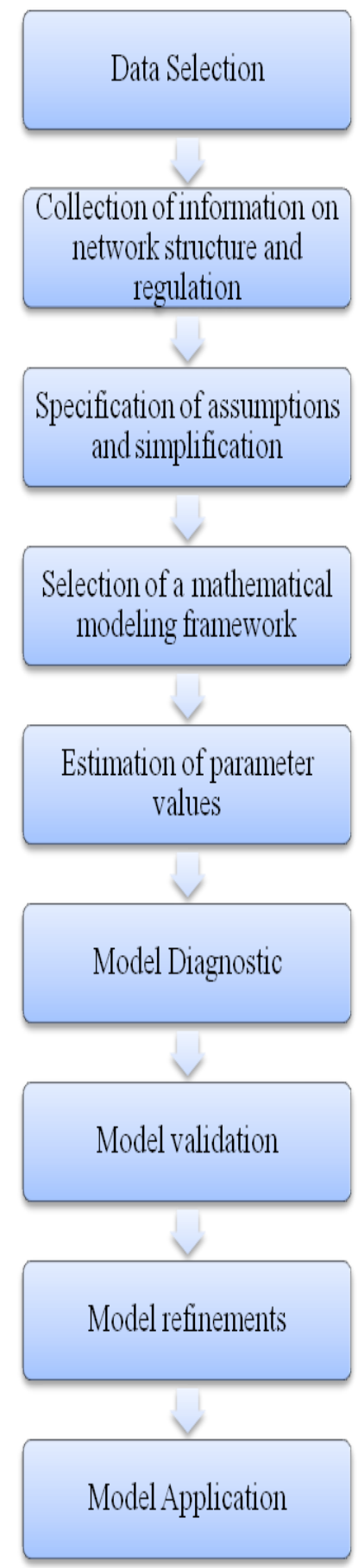

Figure 1 Phases of mathematical modelling [2]

Estimation of parameter values is one of the steps in the modelling process. Parameter estimation helps to determine appropriate numerical parameter values that can convert the symbolic model into a numerical model that consistent with experimental observations [2, 5]. Among the nine phases, parameter values estimation is the most challenging task. This is due to the previous phases of parameter estimation that will affect the difficulties of the estimation. Examples are like the selection of modelling framework, the size and complexity of the hypothesized model and so on. It will be easier if the model is an explicit linear model that uses linear regression methods. Nevertheless, as soon as the model becomes nonlinear, many of these methods will become inapplicable [2].

In addition, biological model is nonlinear and dynamic. Hence, parameter estimation is complex because there is no general solution exists due to the model's nonlinearity. It is easier to analyze if it is a linear model since linear regression methods are used. The mentioned biological model describes the specific phenomena of biological system. It contains parameters that can alter the model behaviour and it can be measured directly or inferred from the data.

Optimization is a scientific discipline that deals with the detection of optimal solutions for a problem, among other alternatives. Optimization models the actual problem by building a proper mathematical function, or called as objective function. Among all feasible solutions where the solution fulfils all the constraints, global optimization tends to find the optimal one [6]. To estimate the parameter in a system, it is necessary to identify the objective function. Then, the objective function will be minimized by using appropriate optimization methods.

In order to simulate the biological system, parameter estimation is the most important phase because with complete and accurate set of parameter value, the system can be characterized. However, it is not always possible to measure these values in wet lab experiments due to high demands on cost and time, since there is no existing general solution to determine the nonlinearity of the dynamic model. Non-linear system is any problem that cannot be written as a linear combination of independent components and thus the result is not directly proportional to the input. As a result, it is difficult to obtain and researchers need to spend more time to solve the system since it needs to carry out the experiment within unknown time in order to get the best result. Furthermore, there are certain parameters which have no appropriate measurement method yet [7]. Exploration of several optimization techniques to minimize cost function is necessary to obtain the optimal value. Based on the research by Syed Murtuza Baker et al. [7] on the estimation of the kinetic parameters of upper part of glycolysis process [7], comparison of several methods were performed and the result stated that Simulated Annealing (SA) took the longest time in order to converge to the best solution. Even though Genetic Algorithm (GA) was able to complete the estimation in a shorter time, it tended to be stuck in local minima. Moreover, Particle Swarm Optimization (PSO) was able to produce better result compared to other methods.

There are several optimization methods in the SBToolbox such as GA [8], SA [9], downhill simplex method [10] and so on. However, there has been no implementation of PSO [11] to estimate kinetic parameters to simulate the essential amino acid metabolism in plant model Arabidopsis Thaliana yet. Arabidopsis thaliana, as a small plant in the mustard family that has turns into the selection for research in plant biology as model system. Focusing on the molecular genetics of this simple plant model has made significant improvements in analyzing plant growth and development. Since the focus of this research is the essential amino acid production, few brief introductions regarding the essential amino acid production process and selected essential amino acids are described. Essential amino acid production is the set of biochemical reactions by which the essential amino acids are generated from potential organisms. Besides, the selected amino acids are Lysine, Threonine, and Isoleucine. These essential amino acids are important to prevent and treat cold sores, to treat various nervous system disorders, and to promote muscle recovery, form haemoglobin, and assist in regulating of blood sugar levels. Furthermore, most of the parameter estimations used other 
algorithms such as SA, GA, EP (Evolutionary Programming) [7] and so on, and completed the set of kinetic parameters for aspartate metabolism by using appropriate method to estimate the kinetic parameter of aspartate metabolism which was not presented.

PSO is one of the methods based on swarm intelligence to estimate the kinetic parameter values. The concept of PSO is that the particles will fly in limited number of directions and have flying experience by their own or with their companion along the search space in certain velocity; and they are expected to fly to the best position.

In this research, PSO is proposed and implemented into SBToolbox in MATLAB to estimate the parameter values of aspartate metabolism in plant model Arabidopsis Thaliana. This method is inspired by bird flocks, fish schools and animal herds when foraging. The significance of the study is that there is no implementation of Particle Swarm Optimization (PSO) into SBToolbox to estimate kinetic parameters to simulate essential amino acid metabolism in plant model, Arabidopsis Thaliana, yet. PSO is a consistent method in estimating parameter values. It takes a shorter time to converge to the best value. It has the ability to find the optima in fast pace. Besides that, very few parameters are needed to adjust in order to obtain the optimal value. PSO is computationally inexpensive in terms of memory requirements and speed [12].

\subsection{METHOD}

Previous works have implemented GA, SA, downhill simplex method, and so on in parameter estimation. In this paper, we propose PSO as a new approach for parameter estimation. In this section, the details of the proposed PSO for estimating parameter values are discussed. The steps involved to obtain optimal parameter values are summarized in Figure 2.

\subsection{Initialization}

Initially, the population array of particles with random positions and velocities on $D$ dimensions in search space was initialized. Then, we defined the number of iterations, inertia weight, positive constant and swarm size. In this study, the inertia weight is 1.0 , the positive constant is 2.0 , and the number of iteration is 100 . Next, the desired optimization fitness function in $d$ variables for each particle was evaluated.

\subsection{Iteration}

In this part, a loop function was used to search and update the best position. There were two values being updated if best values were found in each iteration which were global best- gbest and best solution (fitness solution)- pbest value.

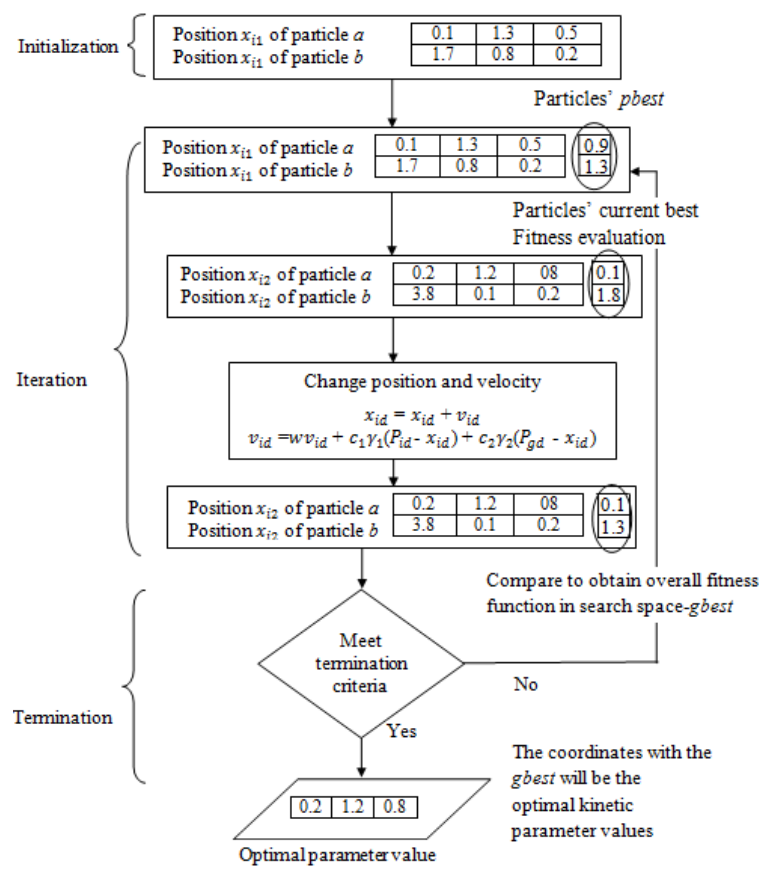

Figure 2 Three steps involved to estimate parameter values using PSO

Initially, the particles' fitness evaluation was compared with particles's pbest. If current value is better than pbest, then set pbest value is equal with the current value and the pbest location equal to the current location in d-dimensional space. Then, we compared fitness evaluation with the population's overall previous best. If current value is better than gbest, then the gbest is reset to the current value. After being updated using Equation 2.1 and 2.2, the optimization fitness function in $d$ variables for each particle was evaluated again.

$$
\begin{aligned}
& x_{i d}=x_{i d}+v_{i d} \\
& v_{i d}=w v_{i d}+c_{1} \gamma_{1}\left(P_{i d^{-}} x_{i d}\right)+c_{2} \gamma_{2}\left(P_{g d^{-}} x_{i d}\right)
\end{aligned}
$$

Where $X_{i}=\left(X_{i 1}, X_{i 2}, \ldots, X_{i D}\right): i^{\text {th }}$ particle's position in search space, $V_{i}=\left(V_{i 1}, V_{i 2}, \ldots, V_{i D}\right): i^{\text {th }}$ particle's velocity, $P_{i}=\left(P_{i 1}, P_{i 2}, \ldots\right.$, $\left.P_{i D}\right)$ : Best position of the $i^{\text {th }}, P_{g}=\left(P_{g 1}, P_{g 2}, \ldots, P_{g D}\right)$ : Best position in the whole swarm, $i=1,2, \ldots, m$, indicates each particle in one population. $d=1,2, \ldots, D$, indicates the number of dimension, $c_{1}$, $c_{2}$ : Acceleration constant representing the pulling of each particle toward pbest and gbest. $\gamma_{1}, \gamma_{2}$ : Random number between 0 and 1 , $v_{i d} \in\left[-v_{\max }, v_{\max }\right], v_{\max }$ : maximum velocity decided by user and $w=$ inertia weight that provides the balance between global and local exploration and exploitation to find a sufficient optimal solution.

\subsection{Termination}

The loop continues until a criterion is met where optimum parameter values are obtained or a maximum number of iteration is reached. 


\subsection{Dataset}

In this research, the dataset used was the aspartate metabolism [13] of Arabidopsis Thaliana. In this research, the kinetic parameters for Lysine, Threonine and Isoleusine were estimated using PSO in SBToolbox [14]. There were 9 kinetic parameters, 16 kinetic parameters, 6 kinetic parameters respectively. Table 1, Table 2 and Table 3 show the list of kinetic parameters that needed to be estimated, experimental values, the kinetic parameters values estimated using SA, downhill simplex method and PSO. The mentioned kinetic parameters play important roles in generating the time series data. With the presence of time series data, we can observe the production for selected amino acids.

Table 1 List of kinetic parameters with measured kinetic parameter values for Lysine

\begin{tabular}{lcccc}
\hline \multicolumn{1}{c}{ Kinetic parameter } & $\begin{array}{c}\text { Measured kinetic } \\
\text { parameter values }\end{array}$ & SA & $\begin{array}{c}\text { Downhill simplex } \\
\text { method }\end{array}$ & PSO \\
\hline Vdhdps1_DHDPS1_k_app_exp & 1 & 0.7019 & 0.9384 & 0.4726 \\
Vdhdps1_DHDPS1_Lys_Ki_app_exp & 10 & 10.1627 & 12.0480 & 10 \\
Vdhdps1_DHDPS1_nH_exp & 2 & 1.8208 & 1.9279 & 1.7768 \\
Vdhdps2_DHDPS2_k_app_exp & 1 & 1.0846 & 10 & 1 \\
Vdhdps2_DHDPS2_Lys_Ki_app_exp & 33 & 33.3325 & 34.5784 & 32.0637 \\
Vdhdps2_DHDPS2_nH_exp & 2 & 2 & 20 & 0.9687 \\
VlysTRNA_Lys_tRNAS_Lys_Km & 25 & 15.0701 & 22.8179 & 35.1274 \\
VlysKR_LKR_kcat_exp & 3.1000 & 0.3430 & 3.1305 & 10.0065 \\
VlysKR_LKR_Lys_Km_exp & 13000 & 121600 & 12350 & 60575 \\
\hline
\end{tabular}

Table 2 List of kinetic parameters with measured kinetic parameter values for Threonine

\begin{tabular}{|c|c|c|c|c|}
\hline Kinetic parameter & $\begin{array}{l}\text { Measured kinetic } \\
\text { parameter values }\end{array}$ & SA & $\begin{array}{c}\text { Downhill } \\
\text { simplex } \\
\text { method } \\
\end{array}$ & PSO \\
\hline Vts1_TS1_kcatmin_exp & 0.42 & 2.9 & 0 & 3 \\
\hline Vts1_TS1_AdoMet_kcatmax_exp & 3.5 & 8.5 & 0.6 & 7 \\
\hline Vts1_TS1_nH_exp & 2 & 1.6 & 1.4 & 0 \\
\hline Vts1_TS1_AdoMet_Ka1_exp & 73 & 19.9 & 160.4 & 526 \\
\hline Vts1_TS1_AdoMEt_Km_no_AdoMet_exp & 250 & 628.4 & 25.8 & 312 \\
\hline Vts1_TS1_AdoMet_Ka2_exp & 0.5 & 0.8 & 0.3 & 3 \\
\hline Vts1_TS1_AdoMet_Ka3_exp & 1.09 & 1.4 & 1.6 & 4 \\
\hline Vts1_TS1_AdoMet_Ka4_exp & 140 & 243.1 & 14.1 & 1045 \\
\hline Vts1_TS1_Phosphate_Ki_exp & 2000 & 2496.3 & 5127.8 & 4844 \\
\hline Vtd_TD_k_app_exp & 0.0124 & 0 & 0 & 0 \\
\hline Vtd_TD_Ile_Ki_no_Val_app_exp & 30 & 3.8 & 57.2 & 139 \\
\hline Vtd_TD_Val_Ka1_app_exp & 73 & 7.4 & 29 & 436 \\
\hline Vtd_TD_Val_Ka2_app_exp & 615 & 4269.4 & 724.1 & 924 \\
\hline Vtd_TD_nH_app_exp & 3 & 29.6 & 7.8 & 10 \\
\hline Vtha_THA_kcat_exp & 1.7 & 0.4 & 0.5 & 2 \\
\hline Vtha_THA_Thr_Km_exp & 7100 & 792.9 & 9178.7 & 57469 \\
\hline
\end{tabular}


Table 3 List of kinetic parameters with measured kinetic parameter values for Isoleucine

\begin{tabular}{lcccc}
\hline \multicolumn{1}{c}{ Kinetic parameter } & $\begin{array}{c}\text { Measured kinetic } \\
\text { parameter values }\end{array}$ & SA & $\begin{array}{c}\text { Downhill } \\
\text { simplex } \\
\text { method }\end{array}$ & PSO \\
\hline Vtd_TD_k_app_exp & 0.0124 & 561.1803 & 0.0229 & 0.0123 \\
Vtd_TD_Ile_Ki_no_Val_app_exp & 30 & 23.7435 & 31.3420 & 75.5376 \\
Vtd_TD_Val_Ka1_app_exp & 73 & 490.6059 & 224.0060 & 460.8398 \\
Vtd_TD_Val_Ka2_app_exp & 615 & 561.1803 & 406.3449 & 352.7619 \\
Vtd_TD_nH_app_exp & 3 & 23.7435 & 7.5509 & 11.0296 \\
VileTRNA_Ile_tRNAS_Ile_Km & 20 & 10.6712 & 5.1853 & 19.9980 \\
\hline
\end{tabular}

\subsection{RESULTS AND DISCUSSION}

In this study, PSO was implemented into SBToolbox in MATLAB to estimate parameter value. Three algorithms; SA, downhill simplex method and PSO were used to estimate the parameters and the result produced by two algorithms were compared. To evaluate the consistency and accuracy of both algorithms, the average of error rate and standard deviation were compared. There were 50 runs for estimating all the kinetic parameters and the formulas used to calculate the standard deviation are as follow:

$$
\begin{aligned}
& e=\sum_{i=1}^{N}\left(y-y_{i}\right)^{2} \\
& A=\frac{e}{N} \\
& S T D=\sqrt{\frac{e}{N}}
\end{aligned}
$$

The Equation 3.1 and 3.2 were used to calculate the error rate and average of error rate. Then, the standard deviation was obtained using Equation 3.3, where $y_{i}$ is simulated results, $y$ is measurement result, $e$ is error rate, $A$ is average of error rate and $N$ is the number of sample. This equation was used to compare the performance of PSO with other methods. The best performance among the methods could be the method with the lower average of error rate and the standard deviation value close to 0 which indicated that PSO was able to produce high accuracy result.

After the discussion on the performance of PSO in estimating kinetic parameters of three amino acids, this section discusses and compares the performance of the three methods including PSO, SA and downhill simplex method. Based on Table 2, the standard deviation values of SA and downhill simplex method did not get close to 0 compared to standard deviation value of PSO. The values were $0.0733,0.1211$ and 0.0113 respectively which PSO had the value that was the closest to 0 . Based on Figure 3, the simulated line produced by PSO that was the closest to experimental line compared to SA and downhill simplex method. PSO had the smallest error rate with 0.0057 while SA and downhill simplex method had 0.0318 and 0.1520 respectively. Having the smallest average of error rate, standard deviation value closer to 0 and simulated line closest to experimental line shows that PSO is a more consistent method to estimate parameter values compared to SA and downhill simplex method. In addition, the computational time for PSO to estimate 9 kinetic parameters was 315.9816 seconds which took a shorter time to complete compared to SA which took 4834.0581 seconds and 585.9037 seconds for downhill simplex method. We have conducted 50 runs with three algorithms and the STD values are shown in Table 2. The results showed that PSO has the lowest
STD value; this indicates that the different between each run is small and this proved that it is a reliable estimation algorithm.

Figures 3, 4, and 5 are the production simulation graphs that are plotted based on the kinetic parameters retrieved from the literature review and mentioned estimation algorithms.

Table 4 Comparison of average of error rate, standard deviation and execution time in seconds between SA, downhill simplex method and PSO for Lysine production from Arabidopsis Thaliana

\begin{tabular}{cccc}
\hline Method & SA & $\begin{array}{c}\text { Downhill } \\
\text { simplex } \\
\text { method }\end{array}$ & PSO \\
\hline $\begin{array}{c}\text { Computational } \\
\text { time (second) }\end{array}$ & 4834.0581 & 585.90371 & 315.98163 \\
$\begin{array}{c}\text { Average of } \\
\text { error rate }\end{array}$ & 0.031796785 & 0.152017 & 0.005688298 \\
$\begin{array}{c}\text { Standard } \\
\text { deviation }\end{array}$ & 0.073336459 & 0.121128 & 0.011252726 \\
\hline
\end{tabular}

Based on Figure 3, the simulated line produced by PSO that was the closest to experimental line compared to SA and downhill simplex method. Having the smallest average of error rate, standard deviation value closer to 0 and simulated line closest to experimental line shows that PSO is a more consistent method to estimate parameter values compared to SA and downhill simplex method. In addition, the computational time for PSO to estimate 9 kinetic parameters was 315.98163 seconds which took a shorter time to complete compared to SA which took 4834.0581 seconds and 585.90371 seconds for downhill simplex method. The smaller average of error rate, standard deviation value closer to 0 and simulated line closest to experimental line shows that PSO is a more consistent method to estimate parameter values compared to SA and downhill simplex method. In addition, the computational time for PSO to estimate 9 kinetic parameters was 315.98163 seconds which took a shorter time to complete compared to SA and downhill simplex method.16 kinetic parameters had been estimated for the production of Threonine in aspartate metabolism. 


\section{Lysine Production Simulation Graph}

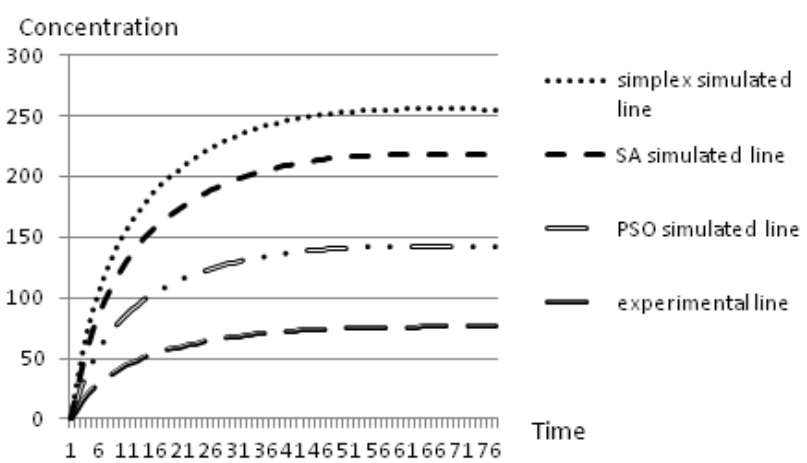

Figure 3 Comparison of simulated line of SA, downhill simplex method and PSO with experimental line for Lysine production

\section{Threonine Production Simulation Graph}

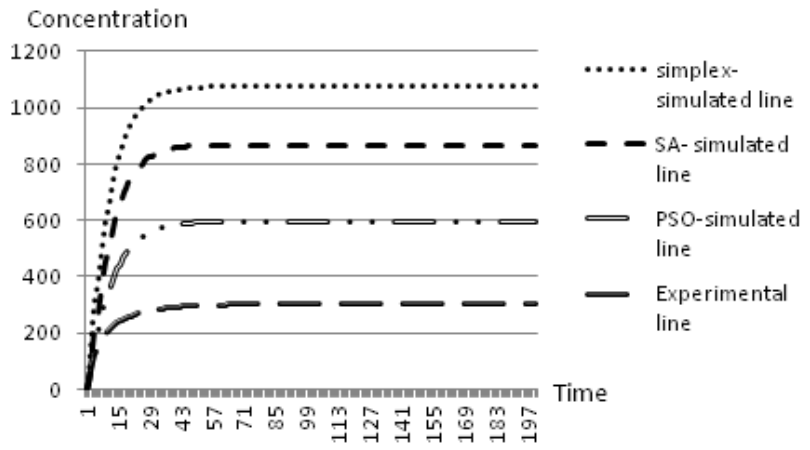

Figure 4 Comparison of simulated line of SA, downhill simplex method and PSO with experimental line for Threonine production

The comparisons of performance measurements are presented in Figure 4 above and Table 5 below. 16 kinetic parameters had been estimated for the production of Threonine in aspartate metabolism. The standard deviation values produced by SA and downhill simplex method were greater than PSO which were $4.44848 \mathrm{E}-07$ and $0.160 \mathrm{E}-07$ accordingly. The standard deviation of PSO was also the smallest- 0.001467E-07 compared to SA and downhill simplex method which had 4.44848E-07 and 0.160E-07 accordingly. In term of computational time, SA consumed more time compared to downhill simplex method and PSO which took 5511.487444 seconds for a complete estimation. For the graph production, the simulated line produced by PSO is the nearest to the experimental line. All the above mentioned criteria indicate that PSO outperformed SA and downhill simplex method in estimating 16 kinetic parameters value of Threonine.
Table 5 Comparison of average of error rate, standard deviation and execution time in seconds between SA, downhill simplex method and PSO for Threonine production from Arabidopsis Thaliana

\begin{tabular}{lccc} 
Method & SA & $\begin{array}{c}\text { Downhill } \\
\text { simplex } \\
\text { method }\end{array}$ & PSO \\
$\begin{array}{l}\text { Computational } \\
\text { time } \\
\text { (second) }\end{array}$ & 5511.487444 & 2983.439710 & 90.26 \\
$\begin{array}{l}\text { Average of error } \\
\text { rate }\end{array}$ & $1.92 \mathrm{E}-07$ & $0.162 \mathrm{E}-07$ & $0.00162 \mathrm{E}-07$ \\
& & & \\
$\begin{array}{l}\text { Standard } \\
\text { deviation }\end{array}$ & $4.44848 \mathrm{E}-07$ & $0.160 \mathrm{E}-07$ & $0.001467 \mathrm{E}-07$ \\
\hline
\end{tabular}

Table 6 Comparison of average of error rate, standard deviation and execution time in seconds between SA, downhill simplex method and PSO for Isoleusine of production in Arabidopsis Thaliana

\begin{tabular}{cccc} 
Method & SA & $\begin{array}{c}\text { Downhill } \\
\text { simplex } \\
\text { method }\end{array}$ & PSO \\
\hline $\begin{array}{c}\text { Feature } \\
\begin{array}{c}\text { Computational } \\
\text { time }\end{array}\end{array}$ & 2910.885082 & 285.011996 & 45.777919 \\
$\begin{array}{c}\text { Averond) } \\
\text { error rate }\end{array}$ & $1.56 \mathrm{E}-15$ & $2.94 \mathrm{E}-15$ & $0.192 \mathrm{E}-15$ \\
$\begin{array}{c}\text { Standard } \\
\text { deviation }\end{array}$ & $2.70 \mathrm{E}-15$ & $5.08386 \mathrm{E}-$ & $0.168 \mathrm{E}-15$ \\
\hline
\end{tabular}

Table 6 shows the comparison of average of error rate and standard deviation for Isoleucine. The comparison table contains information such as computational time, average of error rate and standard deviation. The computational times of SA, downhill simplex method and PSO for estimating kinetic parameters were 2910.885082 seconds, 285.011996 seconds and 45.777919 seconds respectively. In addition, the averages of error rate for the three methods were $1.56 \mathrm{E}-15,2.94 \mathrm{E}-15$ and $0.192 \mathrm{E}-15$. Meanwhile, the standard deviation values of three methods were $2.70 \mathrm{E}-15,5.08386 \mathrm{E}-15$ and $0.168 \mathrm{E}-15$. Among three methods, the performance of PSO was the most consistent method to estimate the kinetic parameters of Isoleucine. This statement is evident by the average of error rate which was the smallest and the standard deviation value of PSO closer to 0 .

Even though Lysine biosynthesis pathway only involved nine kinetic parameters, but it used longest computational time than Threonine (16 kinetic parameters) and Isoleucine biosynthesis pathway (six kinetic parameters). The numbers of enzyme involve in Lysine biosynthesis pathway are higher than the other two biosynthesis pathways. This can be a factor that contributed to complex biosynthesis pathway which requires more computational time for estimation. The enzymes for Lysine 
biosynthesis pathway are Aspartokinase, $\beta$-Aspartate semialdehyde dehydrogenase, Dihydropicolinate synthase, Piperidine-2,6-dicarboxylate dehydrogenase, N-succinyl-2amino-6ketopimelate synthase, Succinyl diaminopimelate aminotransferase, Succinyl diaminopimelate desuccinylase, Diaminopimelate epimerase, and Diaminopimelate decarboxylase [15], whereas there are only five enzymes (aspartokinase, $\beta$-aspartate semialdehyde dehydrogenase, homose rine dehydrogenase, homoserine kinase and threonine synthase) for Threonine biosynthesis pathway [15] and four enzymes (Acetolactate synthase (also known as acetohydroxy acid synthase), Acetohydroxy acid isomeroreductase, Dihydroxyacid dehydratase and Valine aminotransferase) for Isoleucine biosynthesis pathway [15].

In addition, the graph produced as in Figure 5 shows the comparison of experimental line with three simulated lines produced by PSO, SA and downhill simplex method. Before the comparison was made, the lines were in steady-state to ensure the accuracy of the result. The simulated line produced by PSO is the closest to the experimental line. The standard deviation value that is closer to 0 and the small difference between standard deviation value and average of error rate show that the consistency of PSO was high when this method was used to estimate the kinetic parameters value of Isoleucine.

\section{Isoleucine Production Simulation Graph}

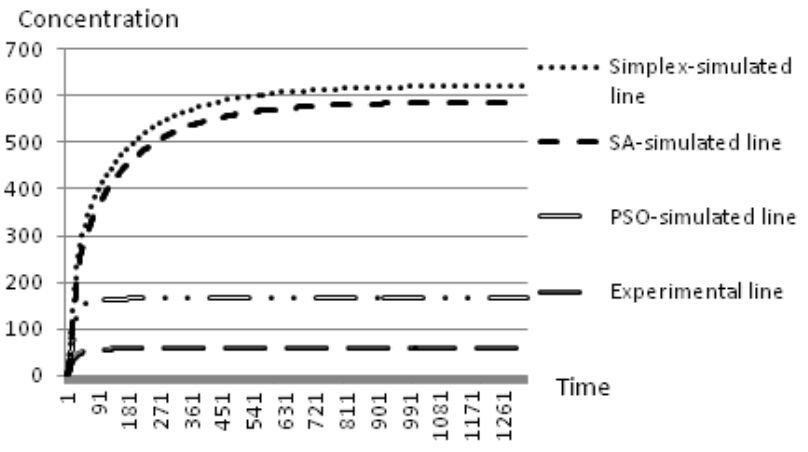

Figure 5 Comparison of simulated line of SA, downhill simplex method and PSO with experimental line for Isoleusine production

PSO had the smallest average of error rate, standard deviation values closer to 0 and the simulated line closer to the experimental line. The results obtained show that PSO outperformed SA and downhill simplex method in estimating kinetic parameters of Lysine, threonine and Isoleucine. It also shows that PSO is the most consistent method used in this research. The use of GA to estimate the kinetic parameters easily gets stuck in local minima and as a result, the accuracy of the kinetic parameters values will be low. This can be solved by using PSO due to the inertia weight taken into account in PSO which was able to avoid being stuck into local minima by increasing the global search ability. The inertia weight produced the balance between the local and global exploration and exploitation. The computational time used to estimate the kinetic parameters is higher by using other algorithms and this can be solved by using PSO, proven by the short time taken in this research. This is the result of PSO which is inspired by bird flocking, fish schooling etc which does not require generation of new population for each iteration, which is time-consuming, but each particle from the same population will fly to better solution in each iteration. Hence, this decreases the time complexity. Furthermore, the steps involved in PSO are less complex compared to other algorithms such as GA which need to undergo selection, mutation and crossover. Besides that, the appropriate acceleration constant in PSO is able to ensure each particle fly towards pbest and gbest, which then lets PSO be able to converge to the best solution faster compared to other algorithms. If the constant value is too low, the particle will tend to move away from the best solution; at the same time the high value of acceleration constant will make the particle pass the target.

\subsection{CONCLUSION}

In conclusion, the performance of PSO in estimating parameter values is better than SA and downhill simplex method after the implementation of PSO into SBToolbox in MATLAB. The simulated results generated by PSO are more consistent, as the standard deviation value is closer to 0 compared to SA and downhill simplex method. The graph also shows that the simulated line of PSO is closer to experimental line. Moreover, the computational time to estimate parameter values for SA and downhill simplex method are longer compared to PSO. This is due to PSO which applies inertia weight to obtain a balance between the local and global exploration and exploitation to avoid getting stuck into the local minima. In addition, PSO takes a shorter time to converge to best solution. Besides that, the acceleration constant that is taken into account in the equation ensures that each particle is pulled towards the pbest and gbest positions. In this research, value 2 was applied. In conclusion, Parameter Estimation through experiment is time consuming, hard and expensive. However, the implementation of PSO into SBToolbox manages to reduce the computational time for parameter estimation. It also reduces the complexity and the cost needed to use to estimate the kinetic parameters since the estimation only involves the use of computer. For future work, the number of run may be increased to ensure the accuracy of the method and more different weight parameters can be implemented to enhance the performance of PSO.

\section{Acknowledgement}

We would like to thank Malaysian Ministry of Higher Education for supporting this research by an Exploratory Research Grant Scheme (Grant number: R.J130000.7807.4L096) and a Fundamental Research Grant Scheme (Grant number: R.J130000.7807.4F190). This research is also funded by an escience research grant (Grant number: 06-01-06-SF1029) from Malaysian Ministry of Science, Technology and Innovation.

\section{References}

[1] A. Abdullah, S. Deris, S. Anwar, S. N. V. Arjunan. 2013. An Evolutionary Firefly Algorithm for the Estimation of Nonlinear Biological Model Parameters. PLOS ONE. 8(3): 1-16.

[2] I. C. Chou, E.O. Voit. 2009. Recent Developments in Paramete Estimation and Structure Identification of Biochemical and Genomic Systems. Mathematical Biosciences. 219: 57-83.

[3] S. Sridharan, S. Gunawan. 2010. Parameter Identifiability of Power-law Biochemical System Models. Journal of Biotechnology. 149(3).132140.

[4] M.P. Little, W.F. Heidenreich, G. Li. 2010. Parameter Identifiability and Redundancy: Theoretical Considerations. PLOS ONE. 5(1): 1-6.

[5] N. Tutkun. 2009. Parameter Estimation in Mathematical Models Using the Real Coded Genetic Algorithms. Expert Systems with Applications, 36(2 part 2): 3342-3345.

[6] K. E. Parsopoulos, M. N.Vrahatis. 2010. Particle Swarm Optimization and Intelligence. New York: Hersey. 
[7] S. M. Baker, K. Schallau, B. H. Junker. 2010. Comparison of Different Algorithms for Simultaneous Estimation of Multiple Parameters in Kinetic Metabolic Models. Journal of Integrative Bioinformatics. 7(3): 133.

[8] C. R. Houck, J. A. Joines, M. G. Kay. 1995. A Genetic Algorithm for Function Optimization: A Matlab Implementation. Technical Report: NCSU-IE-TR-95-09, North Carolina State University, Raleigh, NC.

[9] E. Aarts, J. Korst. 1989. Simulated Annealing and Boltzmann Machines: A Stochastic Approach to Combinatorial Optimization and Neural Computing. New York: John Wiley \& Sons.

[10] J. Nelder, R. Mead. 1965. The Downhill Simplex Method. Computer Journal. 7: 308-313.

[11] R. Eberhart, Y. Shi. 2001. Particle Swarm Optimization: Developments, Applications and Resources. Proc. Congress on Evolutionary Computation, Service Center, Piscataway, NJ. Seoul, Korea.
[12] J. Kennedy, R. Eberhart. 1995. Particle Swarm Optimization. Proc. of IEEE International Conference on Neural Networks (ICNN), Perth, Australia.

[13] G. Curien, O. Bastien, M. Robert-Genthon, A. Cornish-Bowden, M.L. Cárdenas, R. Dumas. 2009. Understanding the Regulation of Aspartate Metabolism Using a Model Based on Measured Kinetic Parameters. Mol. Syst. Biol. 5(271): 1-32.

[14] H. Schmidt, M. Jirstrand. 2005. Systems Biology Toolbox for MATLAB: A Computational Platform for Research in Systems Biology, Bioinformatics. 22(4): 514-515.

[15] D. L. Nelson, M.M. Cox, A. L. Lehninger. 2000. Principles of Biochemistry. New York: Worth Publishing. 